Sociohistórica, $\mathrm{n}^{\circ}$ 42, e063, 2do. Semestre de 2018. ISSN 1852-1606

Universidad Nacional de La Plata.

Facultad de Humanidades y Ciencias de la Educación.

Centro de Investigaciones Socio Históricas

\title{
Conduciendo las áreas técnicas del Estado. Perfiles y trayectorias de funcionarios vinculados a la obra pública durante el gobierno de Videla
}

Luján Menazzi

Instituto de Investigaciones Gino Germani, FSOC - UBA, CONICET, Argentina

Imenazzi@yahoo.com.ar

Cita recomendada: Menazzi, L. (2018). Conduciendo las áreas técnicas del Estado.

Perfiles y trayectorias de funcionarios vinculados a la obra pública durante el

gobierno de Videla. Sociohistórica, 42, e063. https://doi.org/10.24215/18521606e063

Recibido: 02 agosto 2017 - Aceptado: 27 mayo 2018 - Publicado: 3 diciembre 2018

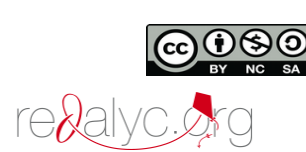

Esta obra está bajo licencia Creative Commons Atribución-NoComercial-CompartirIgual 4.0 Internacional http://creativecommons.org/licenses/by-nc-sa/4.0/deed.es AR 


\title{
Conduciendo las áreas técnicas del Estado. Perfiles y trayectorias de funcionarios vinculados a la obra pública durante el gobierno de Videla
}

\author{
Leading the technical areas of the Argentine State. Profiles and trajectories of civil servants linked to public work \\ areas during Videla's government (1976-1981)
}

Luján Menazzi

Instituto de Investigaciones Gino Germani, FSOC - UBA,

CONICET, Argentina

lmenazzi@yahoo.com.ar

\begin{abstract}
RESUMEN:
El artículo caracteriza las trayectorias profesionales, perfiles disciplinares y ciertas representaciones de los funcionarios nombrados en puestos vinculados a la obra pública durante los primeros años de la última dictadura militar. Siguiendo una metodología histórica de análisis de publicaciones periódicas del universo de la construcción, decretos y currículums, se logra caracterizar los diversos perfiles que predominaron en el período, su vínculo con las propias tradiciones del sector de obra pública y con las diversas orientaciones que convivían al interior del aparato estatal en el contexto del Proceso. A partir de este análisis, se observan fuertes líneas de continuidad en los perfiles de los funcionarios ligados al quehacer de la obra pública, así como orientaciones diversas entre los distintos grupos que ocupaban esas reparticiones estatales, en diálogo con las orientaciones que coexistían al interior del Proceso así como los posicionamientos de los distintos actores del sector.
\end{abstract}

Palabras ClaVe: Dictadura militar, Trayectorias profesionales, Funcionarios, Obra pública, Ingenieros.

\section{Abstract:}

The article characterizes the professional trajectories, disciplinary profiles and certain representations of the civil servants in positions related to public work during the first years of the last military dictatorship. The article uses a historical methodology of analysis which focuses on periodical publications, national decrees and curriculums. Based on those historical sources, the article characterizes the diverse profiles that prevailed in the period, its relation with the previous traditions and with the diverse orientations that coexisted in the interior of the state apparatus. The conclusions show the strong lines of continuity in the profiles of civil servants linked to public work, as well as different orientations among the various groups that occupied these state agencies, in dialogue with the orientations that coexisted in the Dictatorship as well as the positions of the different actors in the sector.

KeYwords: Military dictatorship, Professional trajectories, Civil servants, Public works, Engineers.

\section{INTRODUCCIÓN}

Las burocracias administrativas y los funcionarios de relevancia inciden en la definición e implementación de las políticas públicas y, en este sentido, se constituyen en una excelente vía de entrada para observar al Estado en acción (Palermo, 2006). El análisis de las trayectorias sociales y profesionales de quienes ocupan cargos se vincula con el interés de indagar quiénes gobiernan, qué credenciales se valoran para acceder a los puestos de decisión, cuáles son los saberes considerados relevantes en cada coyuntura y qué universos se articulan en esas trayectorias. El estudio de los elencos gubernamentales tiene antecedentes a nivel local, aunque en términos de Gené (2011), los interrogantes sobre este tema han tendido a ser fragmentarios. Existen diversos abordajes sobre la cuestión. Algunos autores se focalizan en caracterizar el perfil y modalidad de acceso de los elencos (Dalbosco, 2005), otros analizan las destrezas y modos de hacer política de los funcionarios (Gené, 2011), hay trabajos que buscan regularidades históricas analizando elencos en el largo plazo (Giorgi, 2014), y hay quienes se focalizan en determinados niveles gubernamentales y/o carteras (Canelo, 2013; Suriano, 2012, Heredia y Gené, 2009). Algunos temas y períodos han sido particularmente abordados, como el momento de 
conformación de las agencias estatales, la coconstitución de campos profesionales especializados y agencias estatales, y la presencia de elites técnicas en el aparato estatal (Ballent, 2012; Palermo, 2006; Plotkin y Zimmerman, 2012). En este marco amplio de interrogantes, este artículo se focaliza en el análisis de los elencos vinculados a la obra pública durante la primera etapa del autodenominado Proceso de Reorganización Nacional, a partir de la indagación en el perfil y trayectoria profesional de los funcionarios. Se busca analizar el perfil de los funcionarios en un doble sentido. Por un lado, en diálogo con las propias tradiciones del sector de obra pública y por otra parte en el contexto específico de las orientaciones políticas y económicas del Proceso 1 .

El área de obra pública resulta particularmente interesante para analizar estas cuestiones, debido a una serie de características: la importancia económica del sector, los tiempos largos que lo caracterizan (que trascienden muchas veces las temporalidades políticas), el carácter técnico que se le atribuye (en aparente oposición a la lógica política), y la preexistencia y convivencia de tradiciones, valoraciones y compromisos propios de esa comunidad profesional -que comprende a ingenieros, arquitectos, empresarios, funcionarios de carrera y burocracias estatales- que entraban en diálogo tenso con las orientaciones económicas de la Dictadura.

El período resulta de relevancia para el análisis, en tanto la Dictadura se presentó como una ruptura profunda frente a lo inmediato anterior. Sin embargo, tal como señalan numerosos autores, el Proceso se caracterizó por rupturas, pero también por continuidades en diversas áreas de intervención ${ }^{2}$. Así, resulta útil retomar perspectivas que hacen énfasis en colocar a la Dictadura en la trama de sentido de la historia argentina, y no como algo desvinculado de ésta (Quiroga, 2005; Vezzetti, 2002). También se debe indagar la Dictadura en términos cívico-militares, observando el entrecruzamiento de actores civiles y militares en la conformación del entramado social que integró el Proceso (Suriano, 2005). A su vez, en diálogo con los numerosos trabajos que analizan momentos de surgimiento y expansión de las áreas de intervención del Estado y la conformación de elencos gubernamentales, cobra sentido indagar estas agencias estatales en un contexto de supuesta contracción de sus funciones ${ }^{3}$.

A continuación realizaremos una aproximación a estos interrogantes a partir del análisis de los responsables de obra pública durante el gobierno de Videla ${ }^{4}$. Dada la extensión del universo a analizar, se buscó que la revisión de perfiles y trayectorias fuera lo más amplia posible ${ }^{5}$. Nos focalizaremos en los funcionarios nombrados en 1976, aunque en algunos casos, particularmente a nivel provincial, posteriormente hubo intensa rotación de cargos. El período del gobierno del general Videla reviste interés porque, como sostenemos en el artículo se lograron ciertos equilibrios en el área a lo largo de los primeros cinco años de la Dictadura, equilibrios que se quebraron con la asunción del general Viola y el nombramiento de otro elenco de funcionarios para el sector. Analizar el período de Videla por separado del resto de las gestiones de la última dictadura nos permite, por un lado, establecer líneas de continuidad con tradiciones previas en el área, y por otro, dar cuenta de que hubo rupturas posteriores en los perfiles de los responsables, en tanto el Proceso no fue un bloque homogéneo.

La reconstrucción de trayectorias se realizó de modo artesanal cruzando diversas fuentes, principalmente publicaciones periódicas especializadas vinculadas a la construcción, que se hacían eco de los nombramientos y antecedentes de los funcionarios. Se trata de las publicaciones de diversos actores institucionales, como Carreteras (de la Asociación Argentina de Carreteras [AAC]), Informaciones de la Construcción (de la Cámara Argentina de la Construcción [CAC]), Revista La Ingeniería y CAI informa (del Centro Argentino de Ingenieros [CAI]), y el periódico El Constructor. También se recurrió a noticias aparecidas en los medios de comunicación masivos, decretos de nombramientos de los funcionarios, curriculum vitae y bibliografía secundaria que referenciaba trayectorias. Las fuentes consultadas aportan datos acerca de las trayectorias de los funcionarios y reproducen discursos, planes, reuniones e iniciativas en el sector.

Este artículo se enmarca en interrogantes más amplios de investigación, que buscan dar cuenta de diversos actores públicos y privados vinculados al universo de la obra pública, sus articulaciones y el modo en que 
se fueron reformulando estos vínculos a lo largo de diversas coyunturas históricas. En trabajos anteriores se buscó indagar los vínculos entre el gobierno golpista y cámaras empresarias ligadas a la industria de la construcción, actores que, a primera vista, tenían gran afinidad con los postulados ideológicos del Proceso y habían gozado de particular llegada (Menazzi, 2017), y también se avanzó sobre el análisis de la existencia de un universo compartido entre diversos actores institucionales, públicos y privados como organizaciones profesionales, cámaras empresarias y reparticiones estatales cuyos integrantes compartían cierta pertenencia disciplinar, perspectivas acerca del sector y las políticas necesarias para obra pública (Menazzi, 2018). En este sentido, como parte de los análisis de los perfiles profesionales, se hará mención a ciertos posicionamientos de los funcionarios y las relaciones y afinidades con actores institucionales del sector ${ }^{6}$.

El artículo se nutre y dialoga con diversos campos problemáticos. Por un lado, se retomaron análisis sobre elencos gubernamentales, atentos a las credenciales, habilidades, saberes y trayectorias valorados en diversas áreas del Estado en distintas coyunturas históricas. En segundo término, se retoman trabajos que hayan abordado aquellas reparticiones y empresas estatales ligadas a la obra pública, en particular en su vinculación con la conformación del campo disciplinar de los ingenieros. Por último, se dialoga con estudios sobre el período de la Dictadura, en particular aquellos enfocados en las dinámicas gubernamentales y la convivencia de lógicas diversas en el interior del aparato estatal. A lo largo del texto se retoman herramientas metodológicas, perspectivas e ideas de estas diversas líneas analíticas, al tiempo que se dialoga con ellas, en procura de enriquecerlas.

El trabajo se divide en seis secciones que comienzan con la presente introducción. A continuación, se realiza una breve caracterización del área de obra pública en el Estado, sus tradiciones y características. En tercer lugar, se aborda la trayectoria profesional de los funcionarios del período, agrupándolos en tres perfiles: los civiles que desarrollaron su carrera dentro del Estado, los de origen empresario y los de origen castrense. Luego, se realiza una caracterización en términos de continuidades y rupturas de estos grupos respecto a las tradiciones previas del sector. En quinto lugar, se analizan los equilibrios de los distintos grupos que coexistían en el período, en diálogo con otros actores del sector, así como el fin de estos equilibrios a partir de la asunción de Viola. Por último, se dejan planteadas algunas reflexiones.

\section{Algunos APUNTES SOBRE OBRAS PÚBlicas}

Tal como señalan autores como Oszlak y O 'Donnell (1981), y Skocpol (1985) en trabajos ya clásicos, el Estado es un actor en sí mismo y las estructuras burocráticas tienen centralidad en la orientación y alcances de las políticas. Las diversas reparticiones, sus atribuciones, el perfil de los funcionarios y el modo de abordar y resolver aquello que les incumbe resultan de procesos históricos complejos, que están lejos de ser lineales. Si seguimos a Weir y Skocpol (1993), Allison (1993), y Hall (1993), podemos plantear que las tradiciones, las inercias organizacionales, los modos previos de intervenir, los procedimientos establecidos y la permanencia de cuerpos burocráticos en las reparticiones tienen alta incidencia en la formulación e implementación de las políticas, independientemente de los recambios gubernamentales. En este sentido, vale la pena indagar al área de obra pública desde una perspectiva histórica dando cuenta de sus características, perspectivas y orientación y, posteriormente, indagar cómo esas características dialogan con el contexto de la Dictadura.

El Ministerio de Obras Públicas fue creado en 1898, heredando el rol hasta entonces cumplido por la Dirección de Ingenieros. Tal como señalan Ballent (2012) y Palermo (2006), existió un vínculo estrecho de coconstitución entre la conformación de la ingeniería como campo profesional, sus principales instituciones profesionales y universitarias y la formación de reparticiones estatales vinculadas a la obra pública. En términos de Ballent (2012), el Ministerio de Obras Públicas se convirtió en sinónimo de ingeniería nacional. Palermo (2006) se refiere a los ingenieros como constructores del Estado, tanto en su sentido literal como figurado. Las obras públicas como forma de materializar el control sobre el territorio ubicaron en un lugar central a la figura del ingeniero, en tanto portador de un saber técnico específico imprescindible para la 
consolidación del Estado-Nación. Ballent (2012) señala que hacia la década del treinta, el Ministerio de Obras Públicas presentaba una burocracia técnica de un nivel de consolidación fuerte y de un grado de autonomía nada desdeñable. Posteriormente, en términos de Giorgi (2014), el área de obra pública se convirtió en el corazón del Estado empresario, ya que en torno a ésta se agruparon las empresas estatales de energía, servicio, infraestructura y transporte como Ferrocarriles Argentinos, Obras Sanitarias o YPF ${ }^{7}$. Así, se constituyó en un sector del Estado con un manejo importantísimo de fondos, personal y sectores muy sensibles para la economía argentina ${ }^{8}$.

Aun cuando desde la perspectiva de Ballent (2012) la década del treinta marcó el máximo punto de articulación entre ingeniería y Estado, podremos encontrar muchas de las características, valoraciones y representaciones de esas agencias en su momento de conformación y máxima expansión aún vigentes en el período de la Dictadura. Su carácter de agencia estatal técnica, que reivindica cierta racionalidad neutra fundada en saberes expertos, permanecía vigente ${ }^{9}$. Esta representación se veía potenciada en el período por la afinidad electiva entre gobiernos militares y expertise técnica señalada por Heredia y Gené (2009) ${ }^{10}$, así como por el histórico lazo entre el universo castrense y universo de la ingeniería ${ }^{11}$.

Existían, además, otras cuestiones como la autarquía de fondos y la autonomía de la repartición respecto a orientaciones políticas cambiantes que eran valores y anhelos de todos los actores del sector, públicos o privados. Estas cuestiones, que se habían materializado parcialmente en la década del treinta, parecían en el período de la Dictadura inalcanzables ya que el área de Obras Públicas dependía del Ministerio de Economía (en lugar de ser un ministerio autónomo) y los financiamientos específicos para el sector se iban perdiendo, pasando a depender mayormente de oscilantes contribuciones del Tesoro Nacional ${ }^{12}$. También seguía vigente (y reforzada por el contexto), la valoración de las obras con sentido económico por sobre aquellas con sentido social. Tal como analizaremos más adelante, otras valoraciones sobre los perfiles, trayectorias y características de las reparticiones fueron resignificadas, o su sentido invertido, como el tipo de intervención estatal (en que empezaban a difundirse criterios de descentralización), el rol de los actores privados y la valoración de las trayectorias privadas en ámbitos empresariales, en lugar de la valoración de trayectorias dentro del Estado de los funcionarios más importantes.

La jerarquía del Ministerio de Obras Públicas sufrió altibajos a lo largo de su historia, en tanto por momentos hubo numerosos ministerios vinculados al área (Comunicación, Transporte y Obras Públicas), y en otras etapas se constituyó en secretaría, dependiente del Ministerio de Economía, como en el período que nos atañe. Esta pérdida de autonomía fue una cuestión muy resistida por todos los actores vinculados a la construcción, por dentro y por fuera del aparato estatal ${ }^{13}$.

En el período que nos aboca, la Secretaría de Obras Públicas dependía del Ministerio de Economía y tenía a su cargo la Subsecretaría de Obras Públicas (de la cual dependía la Dirección Nacional de Vialidad, la Dirección Nacional de Constructores de Elevadores de Granos y el Servicio Nacional de Arquitectura), la Subsecretaría de Recursos Hídricos (de la cual dependía Obras Sanitarias de la Nación) y la Subsecretaría de Transporte (de la cual dependían Ferrocarriles Argentinos, Subterráneos de Buenos Aires y Aerolíneas Argentinas). Había, además, otras muchas reparticiones de relevancia vinculadas al sector que tenían autarquía o dependían de otras áreas como la Secretaría de Estado de Vivienda y Urbanismo y el Banco Hipotecario Nacional (dependientes del Ministerio de Bienestar Social), Fabricaciones Militares y otras grandes empresas de servicios.

Tal como señalan Schvarzer (1981) y Pucciarelli (2004), entre otros, el Proceso se caracterizó por la tensa convivencia de sectores que sostenían perspectivas económicas diversas. Canelo (2008) indagó las internas del Proceso, y dio cuenta de la compleja coexistencia de varios grupos, entre ellos, sectores liberales y sectores vinculados al complejo militar industrial ${ }^{14}$, que no estaban dispuestos a permitir el desmantelamiento de empresas estatales o resignar la presencia estatal en diversas áreas de la economía. En esta tensión, el sector de obra pública resulta de particular interés en tanto "corazón" del Estado empresario, pero, al mismo tiempo, 
fraccionado en numerosas reparticiones y dependiente (en parte) del Ministerio de Economía, con sus orientaciones liberales. En ese sentido, este artículo se interroga: ¿Quiénes ocuparon las reparticiones ligadas a la obra pública durante la Dictadura? ¿Qué credenciales poseían? ¿Qué afinidades político ideológicas tenían? ¿Qué trayectorias profesionales previas? ¿El golpe de estado supuso cambios en el elenco gubernamental a cargo de este sector? ¿A qué actores del universo de la construcción se interpeló y a quiénes se excluyó?

\section{LOS PERFILES PROFESIONALES DE LOS NUEVOS INTEGRANTES}

Al inicio del Proceso, bajo la gestión del general Videla, se pueden identificar distintos perfiles en los cargos vinculados al quehacer de la obra pública. Caracterizaremos esquemáticamente tres perfiles, agrupando a los funcionarios de acuerdo a sus trayectorias profesionales. Se trata, en primer lugar de funcionarios civiles con una trayectoria dentro del universo estatal, en segundo término funcionarios de origen empresario y, por último, funcionarios de origen castrense ${ }^{15}$.

\section{Los funcionarios de carrera}

Los cargos principales a nivel nacional ligados a la obra pública fueron ocupados por profesionales civiles que tenían larga trayectoria en ese universo, como funcionarios en distintas reparticiones gubernamentales, asesores y/o directivos de grandes intervenciones públicas (complejos hidroeléctricos, puentes internacionales). Se pueden detectar ciertos rasgos comunes si analizamos las trayectorias profesionales del secretario de Estado de Transporte y Obras Públicas, Ing. Federico Camba, ${ }^{16}$ el subsecretario de Obras Públicas, Ing. Federico Alfredo Batrosse; ${ }^{17}$ el subsecretario de Transporte, Ing. Ezequiel Ogueta ${ }^{18}$ y el subsecretario de Recursos Hídricos, Ing. Carlos Ballester ${ }^{19}$. En todos los casos se trata de ingenieros civiles egresados de la Universidad de Buenos Aires con extensas trayectorias en ámbitos de gestión públicos. Es decir, funcionarios de carrera, quienes además sumaban experiencia docente en universidades públicas y publicaciones, estudios y especializaciones en sus áreas de expertise. En la mayor parte de los casos, estos profesionales podían exhibir contactos o participaciones en instituciones vinculadas al quehacer de la obra pública, como AAC, la CAC y el CAI. Evidentemente, se valoraban sus conocimientos técnicos, su trayectoria profesional y su familiaridad con el universo de actores empresarios y profesionales ligados a la obra pública, más allá de su afinidad con la Dictadura. Resulta interesante la elección de funcionarios de carrera para ocupar estos cargos, que pone en evidencia el perfil técnico que buscaba darse al área, a diferencia de lo que ocurría en otros sectores del Estado en que se privilegiaba el desembarco de integrantes de las FFAA.

Este primer grupo de funcionarios se caracterizó por su estabilidad en el cargo a lo largo de la gestión de Videla. Esta duración en el cargo se vuelve inteligible en la medida en que este grupo puede asociarse a la permanencia del propio ministro de Economía. Estos funcionarios lograron conciliar las directivas del ministerio con las demandas del sector, en un proceso no exento de tensiones y conflicto de intereses. En tanto detentaron los cargos más importantes vinculados a la obra pública a nivel nacional y lograron mantenerse en sus cargos a lo largo del gobierno de Videla, podríamos considerar que este primer grupo constituyó el núcleo del sector durante el período.

Con algunas variaciones, este perfil de funcionario, con una carrera mayoritariamente en reparticiones públicas ligadas al sector, se reiteró en otros cargos de relevancia, como Agua y Energía Eléctrica, ${ }^{20}$ la Secretaría de Energía (a partir de 1977) ${ }^{21}$, Gas del Estado ${ }^{22}$, la Secretaría de Estado de Vivienda y Urbanismo ${ }^{23}$, la Dirección de Vialidad de la Provincia de Buenos Aires ${ }^{24}$ y algunos ministerios y/o secretarías de Obras 
Públicas provinciales, como San Juan ${ }^{25}$, donde se nombraron a funcionarios con extensas trayectorias en reparticiones y empresas públicas, con vasta formación profesional en la materia.

\section{Los de origen empresario}

Un segundo perfil que se identifica en puestos de relevancia ligados a la obra pública es el de quienes provenían del universo privado, individuos con relevantes trayectorias en empresas privadas ligadas al quehacer constructor. Es el caso del administrador de la Dirección Nacional de Vialidad, puesto de mucha relevancia dependiente de la Subsecretaría de Obras Públicas, ocupado por el Ing. Gustavo Carmona ${ }^{26}$. Si bien se trataba de un personaje con cierta trayectoria como funcionario público y con inserción docente universitaria, el grueso de su trayectoria profesional se daba como directivo de una importantísima empresa privada dedicada al rubro vial, VIALCO. Al mismo tiempo, Carmona integraba asociaciones vinculadas al sector, como la AAC. En esta misma línea, está quien fuera nombrado por un breve período (1976-1977) director de Ferrocarriles Argentinos, Ing. Antonio Lanusse, con cierta trayectoria en altos cargos públicos (durante gobiernos de facto y por períodos breves), una importante labor en empresas privadas y una activa participación en organizaciones empresarias y profesionales ${ }^{27}$.

A nivel provincial, la práctica de nombrar empresarios prominentes sin experiencia en la función pública fue más frecuente. El caso más saliente en este sentido fue el del ministro de Obras Públicas de la Provincia de Buenos Aires, Ing. Pablo Gorostiaga, uno de los dueños de EACA, importantísima empresa constructora ${ }^{28}$. Gorostiaga tenía amplia participación en las organizaciones vinculadas al sector, como la AAC, la CAC y el CAI, y también exhibía participaciones en espacios de sociabilidad propios de los sectores altos, como el Rotary Club.

En el caso de la provincia de Santa Fe, se nombró inicialmente ministro de Obras Públicas al Ing. Eduardo Oliva, importante empresario y dirigente de la CAC, Delegación Santa Fe (Revista Informaciones de la Construcción, 1976). En el caso de Córdoba se nombró al Ing. Carlos Rouviere, empresario dirigente de la CAC Delegación Córdoba. Se trataba de personajes importantes a nivel local en el sector de la construcción (en el caso de Gorostiaga, era una figura de renombre a nivel nacional e internacional), interlocutores (y partícipes) válidos para el régimen, con trayectorias profesionales y credenciales sociales e ideológicas consideradas apropiadas por los militares. Este perfil, sin embargo, se caracterizó por mayor volatilidad en $\operatorname{los} \operatorname{cargos}^{29}$.

\section{La presencia militar}

Por último, en muchos puestos clave, al frente de las grandes empresas del complejo industrial militar, se ubicó a militares de vasta trayectoria en esas áreas dentro del Estado. Si bien comparten con el primer grupo la trayectoria dentro del universo público, en el primer caso nos referimos a funcionarios civiles, mientras que la característica distintiva de este grupo es su origen castrense. Tal fue el caso de Fabricaciones Militares, donde se ubicó al general Diego Urricarriet, ${ }^{30}$ Servicios Eléctricos de Gran Buenos Aires (SEGBA), donde asumió el Contralmirante Felix Imposti ${ }^{31}$ y la Empresa Nacional de Telecomunicaciones (ENTEL), donde asumió el General Eduardo Corrado ${ }^{32}$, entre muchos otros cargos similares. En términos de Canelo, este grupo se "hallaba vinculado, por trayectoria, a las cristalizaciones institucionales del intervencionismo estatal, y por ideología, a las correspondientes concepciones industrialistas y desarrollistas" (2008, p. 124). Varios de los titulares de estas grandes empresas de Estado forman parte de este grupo. 
Asimismo, en algunas provincias como Entre Ríos y Mendoza se nombró a integrantes de las FFAA en los cargos de ministro o secretario de Obras Públicas ${ }^{33}$. En ocasiones estos integrantes de las FFAA a cargo de grandes empresas o carteras de obra pública tenían formación como ingenieros militares.

\section{CONTINUIDADES Y RUPTURAS}

Esta revisión de perfiles nos permite realizar algunas afirmaciones. En primer lugar, los cargos políticos más importantes a nivel nacional, vinculados al quehacer de la obra pública, quedaron en manos de funcionarios de carrera, con vastas trayectorias en el Estado y gran formación técnica en sus áreas (aunque no habían ocupado previamente los mismos puestos). No se buscó renovar los perfiles ni que esos puestos queden bajo control militar.

Así, tal como señala Giorgi (2014) en su análisis histórico de los perfiles de los titulares de la cartera de Obra Pública, la mayoría de los titulares del área entre 1854 y 2011 provenían de la gestión pública del área, principalmente de

las mismas entrañas de las burocracias ministeriales nacionales, de diversas áreas asociadas a las competencias de estas carteras, pero particularmente de los cargos directivos de los ferrocarriles estatales, de las oficinas de aguas y energía, de diversos centros de ciencia y técnica, además de unos pocos procedentes de la Dirección de Vialidad Nacional (Giorgi, 2014, p. 122).

Esto coincide con los señalamientos de Ballent (2008) acerca de la conformación del elenco del Ministerio de Obras Públicas en la década del treinta:

Efectivamente, ese era un camino que se había consolidado para los años 1930, cuando muchos ingenieros se jubilaban luego de haber desempeñado tareas en el MOP durante toda su vida laboral, ascendiendo desde los cargos técnicos más bajos. También se valoraba la docencia universitaria. Inserción en el Estado, carrera burocrática y enseñanza universitaria eran tres aspectos que se legitimaban mutuamente (Ballent, 2008, p. 834) ${ }^{34}$.

Para continuar con las tendencias propias de los nombramientos en el área de obra pública, la apuesta de la primera etapa del Proceso fue al perfil técnico. Se preservó la expertise del sector y se establecieron más visos de continuidad que de ruptura con las tradiciones previas. En este sentido, podemos afirmar que el área de obra pública se caracterizó por una marcada estabilidad en los perfiles valorados, la cual se sostuvo también durante el período analizado.

Este primer grupo tenía buenos vínculos con las cámaras empresarias y profesionales; eran gente del sector y así se presentaban frente a los empresarios. Manifestaban afinidad con los posicionamientos económicos de Martínez de Hoz, aunque se comprometían a defender la inversión en obra pública. La familiaridad del flamante secretario de Obras Públicas, Ing. Camba, con la CAC se observa, por ejemplo, en estas alocuciones realizadas en un homenaje al Ing. Polledo, quien fuera dirigente de la CAC durante cuarenta años

permítaseme despojarme de la solemnidad y el acartonamiento que seguramente confiere a mi figura la presentación que acaban de hacerme, en calidad de funcionario, en este momento, el que habla es el amigo (...) yo pienso que si la prensa es el cuarto poder, la Cámara Argentina de la Construcción es el quinto (Camba, 1976b, p. 14).

Este tema fue profundizado en un trabajo anterior (Menazzi, 2017), en que se indagan los lazos entre organizaciones empresarias, funcionarios del área de obras públicas y organizaciones profesionales.

Un perfil que se incorporó en ámbitos provinciales y en algunas reparticiones, en sintonía con lo que acontecía en otras áreas, fue el de algunos empresarios notables, con extensas experiencias en el universo privado. En este caso se buscaba que estos empresarios vuelquen sus conocimientos del universo privado a la gestión pública, en un contexto en que se valoraba, aunque con ciertos matices y reticencias, el rol de las empresas privadas y los empresarios ${ }^{35}$. Este grupo de funcionarios tenía afinidad con los postulados liberales, 
y pertenencia común con el universo de empresarios y dirigentes empresarios. Así, Carmona afirmaba como balance de su gestión

\begin{abstract}
...nuestra gestión que ha estado fundada en los sólidos pilotes del Federalismo practicando con convicción, en el convencimiento que la verdadera acción del Estado es subsidiaria de los que tienen la responsabilidad directa de la ejecución. Esta ejecución debe estar en manos de la actividad privada, aceptando la premisa de que todo lo que es especificable y medible es contratable y si a esta contratación se llega por el camino de una economía de libre competencia, el éxito de la gestión está asegurado (Carmona, 1980, p. 9)
\end{abstract}

No podemos afirmar que este perfil resulte novedoso dentro del Estado, o incluso dentro de la repartición. Lo que sí puede considerarse novedoso es la valoración de la trayectoria en el ámbito privado por sobre la trayectoria en el ámbito público, al contrario de lo que aconteciera en períodos previos. Tanto desde el ámbito privado como desde el ámbito público se señalaba que quienes se integraban al Estado viniendo de cargos privados realizaban un patriótico sacrificio y tenían la idoneidad moral y la experiencia como para salvar la situación crítica. La idea era que volcaran los conocimientos y saberes del ámbito privado al universo público. Un ejemplo ilustrativo de esto se observa en la siguiente declaración acerca de Pablo Gorostiaga, realizada por el Arq. Marcelo Roggio, integrante de una prominente empresa y presidente de la CAC

Toda esta lista de su intensa como exitosa actuación profesional deportiva y social, culminó el 10 de abril de 1976 al ser nombrado Ministro de Obras Públicas de la Provincia de Buenos Aires, donde pudo volcar sus conocimientos y capacidad, con entusiasmo de verdadero patriota, transfiriendo el peso de la responsabilidad empresaria, de sus propios intereses al bien común del país (Roggio, 1980, p. 43).

Desde esta perspectiva, la experiencia en el universo privado era mucho más valiosa que en el universo público. En una nota al secretario de Estado de Vivienda y Urbanismo, Ing. Canedo Peró, se afirmaba

...no le inspiran respeto los profesionales que, apegados a las funciones públicas se conforman con las reducidas posibilidades que éstas les ofrecen, sustrayéndose a la experiencia competitiva prevaleciente en el ámbito privado. Los diarios están llenos de avisos que piden ingenieros -dice-, y no comprendo qué interés profesional o económico pueda hacerles optar por retener un puesto público (Canedo Peró, 1979, p. 25).

Tal como mencionamos previamente para otro período, Ballent (2008) da cuenta de una valoración inversa respecto a las trayectorias públicas y privadas.

La presencia de militares a cargo de empresas del complejo industrial militar tampoco resulta novedosa, en tanto se trataba de grandes empresas que fueron controladas por militares e ingenieros militares bajo numerosos gobiernos. También aquí podría pensarse que se establecen ciertas líneas de continuidad más que de ruptura. Tal como analiza Canelo (2008), los militares a cargo de grandes empresas de Estado tenían una convicción industrialista: consideraban que el Estado debía sostener una presencia fuerte en la economía. Este grupo tenía una postura de defensa de las empresas de Estado que colisionaba con los postulados del Ministerio de Economía y con los actores empresarios del universo de la construcción, que apoyaban posturas liberales ${ }^{36}$. Sus posturas, sin embargo, tenían cierta afinidad con la de organizaciones profesionales como el CAI, que sostenía perspectivas desarrollistas contrarias a la orientación liberal ${ }^{37}$.

A su vez, la omnipresencia de ingenieros (en particular, ingenieros civiles) en esta área no hacía más que profundizar una tradición previa, en que la predominancia de los ingenieros iba ganando terreno en el área de obras públicas, incluso en cargos directivos. La idea de que los ingenieros eran los destinatarios naturales de los cargos vinculados a la obra pública era una concepción que permaneció inalterada a lo largo del tiempo.

En el período analizado, tal omnipresencia de los ingenieros era una cuestión valorada y reivindicada por los responsables de obra pública:

Este gobierno ha reconocido - quizá como ningún otro en la historia del país- el papel fundamental que les corresponde a los profesionales de la ingeniería en la dirección y conducción de las áreas técnicas del Estado. Creo, por consiguiente, que por primera vez se ha disipado la fundada queja de antaño: hoy, los ingenieros se hallan al frente de la mayoría de las reparticiones donde sus conocimientos son primordiales. Ello no sólo ocurre en la secretaría a mi cargo, en la cual todos los subsecretarios y 
administradores de empresas - con una sola excepción- son ingenieros, sino también en el resto de la administración pública y empresas del estado tales como YPF, Gas del Estado, Agua y energía, Hidronor, etc. (Camba, Secretario de Estado de Transporte y Obras Públicas, 1979, pp. 28-29).

La idea de que la conducción de las áreas técnicas del estado correspondía a los ingenieros se asociaba también con la representación sostenida por integrantes de la Dictadura y la autorepresentación de los propios profesionales de la ingeniería, que asociaban su profesión con un rol técnico, neutro y apolítico que correspondía al sector de obra pública, alejado de partidismos ${ }^{38}$.

Si bien parecería haber continuidades en los perfiles profesionales de quienes ocupan los cargos vinculados a obra pública, vale la pena analizar cómo esos perfiles profesionales, tradiciones y cosmovisiones propias de las reparticiones vinculadas a la obra pública se pusieron en diálogo con el contexto de la Dictadura, en que se pregonaba un achicamiento del Estado y una reformulación de su rol. Si la mayor parte de los análisis de las reparticiones vinculadas a la obra pública se focalizan en contextos de expansión del aparato estatal (Ballent, 2012; Palermo, 2006; Regalsky y Salerno, 2005; Salerno, 2015), ¿qué sucede en momentos de contracción?; ¿cómo dialogan las tradiciones y valoraciones propias de ciertas reparticiones con una coyuntura política en que primaron otras lógicas en el interior del aparato estatal?

\section{EL JUEGO DE EQUILIBRIOS Y FIDELIDADES}

El panorama inicial de la gestión Videla en el sector de la obra pública suponía ciertos equilibrios. Por un lado, los funcionarios de carrera, quienes retenían los puestos más importantes, sintonizaban con la política económica y con los dirigentes empresarios vinculados a la construcción. Este grupo sostenía algunas de las miradas y perspectivas tradicionales del sector, como la valoración de la obra pública, la defensa de la autarquía de las reparticiones vinculadas al sector, la reivindicación de la expertise técnica como merecedora natural de los cargos y al área como ámbito de incumbencia profesional de los ingenieros.

Sin embargo, estas valoraciones, que tenían sus raíces en la propia conformación de las reparticiones, convivían con lineamientos políticos propios del período: la búsqueda de achicar y racionalizar el Estado (que en 1977 ya suponía la expulsión de 50.000 agentes del área de obra pública, número detentado con orgullo por el responsable de la cartera [Camba, 1977]), la búsqueda de descentralizar la realización y financiamiento de las obras y los intentos de aplicar el principio de subsidiaridad del Estado.

Esta doble fidelidad (hacia las necesidades del sector y hacia las políticas del gobierno) era manifestada con claridad por Camba

Cuando un hombre, cualquiera sea su procedencia, su especialidad específica -ya sea que provenga del sector profesional o empresarial-, accede a niveles de Gobierno, debe sumarse a la labor de un equipo, debe integrarse a una política global y a veces -aunque no siempre ocurre así-, deponer la defensa cerrada de intereses sectoriales en beneficio de un interés más general, pero en definitiva tiene a la vista también el progreso y la protección de los intereses del sector. Comprometo desde ya -aunque resulte obvio para quienes conocen mi trayectoria- que el apoyo a la obra pública a través de mi gestión y de mis colaboradores no será de ninguna manera retaceado, sino por el contrario, en la medida de las posibilidades que el país y el sector económico pueda acordarnos, ella tendrá el apoyo que se merece (1976a , p. 8).

En sintonía con estas últimas cuestiones, una mirada novedosa y claramente disruptiva respecto a tradiciones previas del sector se vinculaba con la valoración del rol de los privados, fuera como actores empresarios subsidiarios del Estado, fuera como funcionarios de origen empresario que venían a volcar su conocimiento al Estado e intentar trasladar las pautas de eficiencia del universo privado al ámbito público. Así, si respecto a la década del treinta Ballent (2008) señalaba que las representaciones de las trayectorias profesionales tenían un carácter estadocéntrico, en el período de la Dictadura, se valoraba y alababa particularmente el tránsito por ámbitos privados.

Si seguimos esta lógica, los funcionarios de origen empresario también articulaban la valoración de ciertas cuestiones tradicionales del sector con los postulados económicos sostenidos por el Ministerio de Economía. 
En este caso se profundizaba la mirada crítica sobre el rol del Estado y la necesidad de su retiro y/o achicamiento.

Estos dos grupos actuaron al unísono y en armonía con las entidades empresarias más importantes durante el período.

El tercer grupo, el de los militares a cargo de empresas de Estado, tenía una perspectiva opuesta a los postulados liberales, y defensiva respecto al complejo industrial militar. A causa de estos postulados, tenían cierta afinidad con algunas agrupaciones profesionales de perspectiva desarrollista como el CAI. En estos espacios se criticaba el desmantelamiento de áreas del Estado, la pérdida de profesionales en diversas reparticiones y el proceso desindustrializador, todo lo cual veía como consecuencia de las políticas económicas implementadas.

En este sentido, podemos afirmar que los quiebres o diferencias en el interior del Estado, en las carteras vinculadas a la obra pública, daban cuenta de las internas del propio gobierno militar, pero también reflejaban especificidades y grietas entre actores del sector de la obra pública ${ }^{39}$.

A pesar de estas diferencias, podríamos pensar que la mayor parte de las decisiones de obra pública estaban bajo control del grupo de funcionarios de carrera y aquellos provenientes del universo privado, mientras que los funcionarios de origen militar controlaban las empresas de Estado. Éstas tenían enorme relevancia económica y poder de decisión en sus áreas de intervención, pero no poseían tanta injerencia en cuestiones como las regulaciones a la obra pública y las negociaciones con las empresas. En este sentido, podríamos pensar que existía cierto precario equilibrio que evitaba choques explícitos en el sector.

Tal como se indagó en trabajos previos, la afinidad entre los funcionarios de carrera, los de origen empresario y las cámaras empresarias del sector -como la CAC y la AAC-se tradujo en vínculos estrechos durante el período, y acuerdos básicos respecto a algunas orientaciones políticas. Estos acuerdos implicaban sostener posturas liberales y antiestatistas, aplicar el principio de subsidiaridad del Estado, achicar las plantas de las reparticiones estatales, ordenar, descentralizar, conseguir financiamiento genuino y, al mismo tiempo, sostener un flujo importante de fondos para la obra pública (Menazzi, 2017) ${ }^{40}$.

En paralelo, según denunciaban los empresarios del sector, algunos de aquellos ámbitos dirigidos por funcionarios de origen castrense (en particular, las empresas de Estado) se resistían a los intentos de achicamiento, racionalización y desmantelamiento.

Los equilibrios y distribución de cargos de la era Videla se vieron profundamente alterados con el arribo del general Viola a la presidencia de la república. Por un lado, la asunción de Viola supuso ciertas "buenas nuevas" para los dirigentes empresarios y profesionales vinculados a la construcción, en tanto se creó el Ministerio de Obras Públicas, vieja demanda del sector.

Sin embargo, se fortaleció la presencia de militares de posturas industrialistas y defensores del intervencionismo estatal en los máximos cargos de responsabilidad en obras públicas, en detrimento de funcionarios de carrera y de origen empresario. Así, el Gral. Diego Urricarriet quedó a cargo del flamante Ministerio de Obras Públicas y el Brigadier Mayor (RE) Desimoni quedó a cargo de la Dirección Nacional de Vialidad. Como subsecretario de Obras Públicas se nombró al Ing. Dante Guerrero, quien, si bien no era militar de profesión, había trabajado 35 años en el comando de ingeniería del ejército y había dirigido empresas de Estado, con a un perfil afín al del grupo de militares.

Esto supuso un quiebre en los acuerdos y cosmovisiones compartidas que primaron durante la gestión Videla, y un deterioro en el vínculo del gobierno militar con las Cámaras empresarias del sector. Ciertos acuerdos básicos como el principio de subsidiaridad del Estado, la importancia de sostener ingentes fondos para obra pública y los diagnósticos acerca de la situación del sector se quebraron, y se establecieron visiones contrapuestas entre los funcionarios más importantes del sector y los actores empresarios de la construcción 41. 


\section{Conclusiones}

En diálogo con diversos campos problemáticos, el artículo buscó dar cuenta de los perfiles profesionales de los funcionarios responsables del área de obra pública durante el gobierno del general Videla. A partir del repaso por los distintos perfiles que primaron en el período, su vínculo con tradiciones previas y con las diversas orientaciones que convivían en el interior del aparato estatal, se pueden esbozar algunas reflexiones.

Una primer cuestión refiere a la matriz continuidad/ruptura al analizar la última dictadura militar. Tal como señalan Franco y Lvovich en sus reflexiones sobre el campo de la historia reciente,

...se trata de insertar la dictadura en un continuum histórico en el cual, sin perder las marcas específicas que singularizan al período, la ruptura histórica no resulte el único organizador de preguntas y problemas. Es preciso multiplicar los estudios que den cuenta de sus cambios, pero también de la permanencia de las lógicas burocráticas y de las múltiples formas de interpenetración entre el Estado y la sociedad civil (Franco y Lvovich, 2017, p. 206).

A este respecto, la revisión de perfiles del área de obra pública pone en evidencia la existencia de fuertes líneas de continuidad con períodos previos en las credenciales valoradas para asumir los cargos directivos del sector. En estos puestos primaron los funcionarios que habían desarrollado su carrera en el aparato estatal, como había sucedido históricamente en el área. También, en continuidad con las tradiciones previas, tenían fuerte presencia aquellos funcionarios de origen militar, y, para sintonizar un poco más con la tónica del período, se sumaba la presencia de algunos funcionarios de origen empresario. En este sentido, los perfiles de los funcionarios dialogan fuertemente con las propias tradiciones de las reparticiones del sector y con sus características históricas, independientemente de la coyuntura específica.

A su vez, más allá de la continuidad en los perfiles, se observa una modificación en las valoraciones de las trayectorias profesionales. El desempeño en el universo privado, antes subestimado (aunque presente), pasa a ser un antecedente de privilegio para ocupar cargos estatales.

Si en el perfil de los elencos se observan continuidades, las novedades se observan en ciertas políticas instrumentadas (descentralización, racionalización del aparato estatal), más ligadas a los designios generales del Proceso. Aun así, las transformaciones no tuvieron la profundidad esperada por los empresarios de la construcción (en particular, las privatizaciones y la aplicación del principio de subsidiaridad del Estado [Menazzi, 2017]). Estas novedades, sin embargo, convivían con valoraciones y lógicas tradicionales del sector, como la voluntad de sostener importantes fondos para obra pública, la valoración de los perfiles técnicos, y la defensa de la autarquía financiera y la autonomía de las reparticiones.

A su vez, otra cuestión refiere a que la coexistencia de estos distintos perfiles supuso orientaciones a veces contrapuestas acerca del sector. Estos diversos perfiles se vinculan tanto con las grietas internas del gobierno militar respecto a posturas liberales y defensoras del complejo industrial militar, como con grietas internas del propio sector de obra pública, en el que coexistían actores empresarios de fuerte orientación liberal y actores profesionales con perspectivas desarrollistas. En este punto cobra sentido la búsqueda de interpretar a la Dictadura en la trama de sentido de la historia argentina, y no como algo externo. Las distintas facciones del Proceso sostuvieron alianzas con múltiples actores con orientaciones y perspectivas diversas, que preexistían al golpe de Estado. La trama de alianzas, internas y enfrentamientos no hace más que replicar y profundizar enfrentamientos de la sociedad civil, en un diálogo complejo con aquellas internas de las propias Fuerzas Armadas.

Si la gestión de Videla supuso una aparente continuidad en el perfil de los funcionarios y un tenso equilibrio entre diversos grupos, la gestión Viola implicó modificaciones en los equilibrios entre los diversos actores del área de obra pública. Los funcionarios de origen castrense cobraron protagonismo, y terminaron por quebrar el predominio de funcionarios de carrera o de origen empresario. Esto resulta interesante, en la medida en que pone en evidencia que así como se pueden observar continuidades entre el Proceso y gobiernos previos, 
también se pueden observar rupturas en las orientaciones políticas de esta área en particular entre las distintas gestiones del Proceso ${ }^{42}$.

Otra cuestión a señalar se vincula con la incidencia de ciertos profesionales sobre las políticas públicas en diversas coyunturas. Tal como señalamos, si bien los perfiles técnicos que habitualmente ocupaban los cargos del sector continuaron haciéndolo durante la gestión Videla, tuvieron que lidiar con las orientaciones económicas propias del período, reformulando y resignificando tradiciones previas. En este sentido, los técnicos y profesionales se insertan en determinadas coyunturas políticas, e intentan poner en diálogo las tradiciones y valoraciones que caracterizan a determinado origen disciplinar y a determinadas reparticiones estatales con los contextos políticos más generales. A su vez, el perfil que predominó durante la gestión de Videla se vio desplazado al asumir Viola. En este sentido, podemos retomar a Palermo (2006), quien indica que no es posible generalizar la capacidad de influencia de las elites técnicas en diversas coyunturas políticas.

Este acercamiento a la cuestión abre nuevos interrogantes que resultan interesantes para profundizar. Por un lado, las orientaciones políticas del sector en el período, cuestión que mencionamos muy lateralmente pero que amerita ser analizada. En segundo término, el análisis de los diversos actores intervinientes en el sector, sus vínculos y perspectivas. Mencionamos brevemente la existencia de actores institucionales con perspectivas diversas sobre las necesidades del sector. Vale la pena analizar sus alianzas y su llegada al poder en diversas coyunturas políticas. Por último, una cuestión mencionada que reviste interés es el vínculo entre los ingenieros como grupo profesional y las áreas técnicas del Estado. La misma fue analizada para otros períodos (Ballent, 2008, Palermo, 2006), pero continúa teniendo relevancia en coyunturas más recientes.

\section{Fuentes}

Academia Nacional de Ingeniería. (2005). Anales de la Academia Nacional de Ingeniería. Tomo 1. Buenos Aires: Academia Nacional de Ingeniería.

Ballester, C. (2018). Currículum Vitae. Linkedin. Argentina. Disponible en: https://ar.linkedin.com/in /carlos-a-ballester-caballester-2230a168

CAC. (2006). Estudio de las capacidades y problemas en la industria de la construcción de infraestructuras, Informe Final. Buenos Aires: Fondo para el desarrollo de la Construcción.

Camba, F. (2 de junio de 1976a). Disertación Ing. Camba. Revista Informaciones de la Construcción. Nro, 571, pp. 7-8.

Camba, F. (4 de agosto de 1976b). Discurso por el 40 aniversario de la Cámara Argentina de la Construcción y Homenaje a Cesar Polledo. Revista Informaciones de la Construcción. Nro. 580, pp. 9-16.

Camba, F. (30 de noviembre de 1977). Palabras del Ing. Camba. Revista Informaciones de la Construcción. Nro. 649, pp. 12-14.

Camba, F. (Mayo de 1979). Discurso en la Semana de la Ingeniería. Revista CAI Informa. Año XVI, Nro. 311, pp. 28-32.

Camba, F. (31 de octubre de 1980). Presidió el Ing. Camba el Acto de Clausura de las Terceras Jornadas de Obra Pública. Revista Informaciones de la Construcción. Nro. 801, pp. 9-14.

Carmona, G. (4 de octubre de 1976). Encuesta vial. Periódico El Constructor. Año LXXV N 3.424, pp. 6-10..

Carmona, G. (octubre - diciembre 1980). Disertación del Ingeniero Carmona. Revista Carreteras. Año XXV. Nro. 96, pp. 6-9.

Constantini, A. (Marzo de 1981). Llamado de atención a las autoridades acerca de la magnitud de la crisis imperante. Revista CAI informa. Año 18, Nro. 330, pp. 7-10.

Constantini, A. (2 de junio de 1976).Palabras del Ing. Alberto Constantini. Revista Informaciones de la Construcción. Año 13, Nro. 571,pp. 3-4.Constantini, A. (Agosto de 1980). Ni en contra ni a favor de ningún Proceso, sólo por el interés nacional. CAI informa. Año 17, Nro. 323, pp. 11-15. 
Coria Jofre, D. (2018). Currículum Vitae. Disponible en: http://www.geocities.ws/guanacaches/curr_d ocj.html

Fundación Konex. (2018). Pedro Vicien. Jurado Premios Konex 1993 Ciencia y Tecnología. Fundación Konex. Buenos Aires. Disponible en: http://www.fundacionkonex.org/b517-pedro-vicien

Philip, G. (1982). Oil and Politics in Latin America. New York: Cambridge University Press.

Polledo, C. (2 de junio de 1976). El Ingeniero Cesar M. Polledo habló en el Centro Argentino de Ingenieros sobre la evolución de la construcción. Revista Informaciones de la Construcción, Nro. 571, pp. 3-6.

Reggini, H. (26 de octubre de 2018). Homenaje al Ing. Pedro Vicien con Referencias a los Sistemas Procognitivos Vislumbrados por R. Buckminster Fuller y J. C. Licklider. Conferencia pronunciada por el Ing. Horacio C. Reggini en la Academia Nacional de Ciencias de Buenos Aires. Disponible en: http://www.cien cias.org.ar/user/DOCUMENTOS/Reggini2.pdf

CAI. (marzo de 1979). Plan de Viviendas: 700 millones de dólares en 1979. Revista CAI Informa Nro, pp 24-26.

Asociación Argentina de Carreteras. (abril - junio 1976a). El Ingeniero Camba es el Nuevo Secretario de Estado de Transporte y Obras Públicas de la Nación. Revista Carreteras, Año XXI, Nro. 78, p. 12.

Asociación Argentina de Carreteras. (abril - junio de 1976b). Nuevos Subsecretarios de Transporte y Obras Públicas. Revista Carreteras, Año XXI, Nro. 78, p. 12.

Asociación Argentina de Carreteras. (abril - junio de 1976c). El Ingeniero Gustavo R. Carmona asumió el cargo de Administrador General de Vialidad Nacional. Revista Carreteras, Año XXI, Nro. 78, p. 16.

CAC. (2 de junio de 1976). El presidente de la Delegación Santa Fe de la Cámara Argentina de la Construcción fue designado Ministro de Obras Públicas de esa provincia. Revista Informaciones de la Construcción, Nro. 571, p. 9.

CAC. (12 de enero de 1977a). El Día de la Construcción en el interior. Revista Informaciones de la Construcción, Nro. 602-603, pp. 6-12.

CAC. (27 de enero de 1977b). La semana de la construcción en el interior del país. Revista Informaciones de la Construcción, Nro. 604-605, pp. 4-14.

CAC. (2 de febrero de 1977c). El Día de la Construcción en el interior del país. Revista Informaciones de la Construcción, Nro. 606, pp. 4-16.

CAC. (21/28 de octubre de 1980). Fue agasajado en la Cámara Argentina de la Construcción el Ing. Pablo Gorostiaga. Revista Informaciones de la Construcción, Nro. 804/805, pp. 40-43.

CAC. (1981a). "Asumió el cargo de Ministro de Obras Públicas el Gral. de Div. (R.E.) Diego Ernesto Urricarriet”. Revista Informaciones de la Construcción, Nro. 823. 3 de abril de 1981. P. 4.

CAC. (3 de julio de 1981b). Trayectoria del Ing. Lanusse. Revista Informaciones de la Construcción. Nro. 826, p. 5.

Roggio, M. (21/28 de noviembre de 1980). Fue agasajado en la Cámara Argentina de la Construcción el Ing. Pablo Gorostiaga. Revista Informaciones de la Construcción, Nro. 804/805, pp. 40-43.

Universidad Tecnológica Nacional. (2018). Historia de la UTN. Buenos Aires: UTN. Disponible en: h ttp://transmedia.frba.utn.edu.ar/

\section{REFERENCIAS}

Acuña, C. (1988). Empresarios y política. La relación de las organizaciones empresarias con regímenes políticos en América Latina: los casos argentino y brasileño. Boletín Informativo de Techint, 255. 17-45.

Allison, G. (1993). Modelos conceptuales: La crisis de los misiles cubanos. En L. Aguilar Villanueva [ed.], Antología de Politicas Públicas (pp. 119-200). México: Porrúa.

Ballent, A. (2008). Ingeniería y Estado: la red nacional de caminos y las obras públicas en la Argentina, 1930-1943. História, Ciências, Saúde - Manguinhos, 5(3), 827-847. 
Ballent, A. (2012). Burocracia, técnica y política: los ingenieros del Ministerio de Obras Públicas y los golpes de Estado (1930-1943). Trabajo presentado en Segundo Taller de Trabajo Construcción del Estado y Burocracias Técnicas en América Latina. Siglos XIX y XX, noviembre. Buenos Aires: IDES.

Bellini, C. y Rougier, M. (2008). El Estado empresario en la industria argentina. Conformación y crisis. Buenos Aires: Manantial.

Beltrán, G. (2007). La acción empresaria en el contexto de las reformas estructurales de las décadas de los ochenta y noventa en Argentina (Tesis de doctorado inédita), Universidad de Buenos Aires, Facultad de Ciencias Sociales, Argentina.

Birle, P. (1997). Los empresarios y la democracia en la Argentina. Conflictos y coincidencias. Buenos Aires: Universidad de Belgrano.

Canelo, P. (2008). El Proceso en su laberinto. La interna militar de Videla a Bignone. Buenos Aires: Prometeo.

Canelo, P. (2013). El gobierno del "Proceso" en el nivel provincial. Reclutamiento, rol y carreras políticas de los interventores y gobernadores de la última dictadura militar argentina (1976-1983). Trabajo presentado en $X$ Jornadas de Sociología. Buenos Aires: Facultad de Ciencias Sociales, Universidad de Buenos Aires.

Canelo, P. (2016). La militarización del Estado durante la última dictadura militar argentina. Un estudio de los gabinetes del Poder Ejecutivo Nacional entre 1976 y 1983. Historia Crítica, 62, 57-75.

Castellani, A. (2009). Estado, empresas y empresarios. La difusión de ámbitos privilegiados de acumulación en la Argentina entre 1966 y 1989. Buenos Aires: Prometeo.

Dalbosco, H. (2005). Perfil de los funcionarios políticos 1983-1999. Trabajo presentado en 3er. Congreso Argentino de Administración Pública Sociedad, Gobierno y Administración. San Miguel de Tucumán, 2, 3 y 4 de Junio de 2005.

Dominguez Roca, L. (2005). Planes urbanos y transporte en la Ciudad de Buenos Aires. Scripta Nova Revista electrónica de Geografia y Ciencias Sociales, IX(194), s/p.

Franco, M., y Lvovich, D. (2017). Historia reciente. Apuntes sobre un campo de investigación en expansión. Boletín del Instituto de Historia Argentina y Americana "Dr. Emilio Ravignani”, Tercera serie, 47, 190-217.

Gené, M. (2011). En torno a los profesionales de la política. Trayectorias, prácticas y destrezas en el ejercicio del poder político desde el estado. Revista Perspectivas de Politicas Públicas, 1(1), 85-107.

Giorgi, G. (2014). Ministros y ministerios de la Nación argentina: un aporte prosopográfico para el estudio del gabinete nacional (1854-2011). Apuntes: Revista de ciencias sociales, XLI(74), 103-139.

Hall, P. (1993). Policy Paradigms, Social Learning and the State: the Case of Economic Policy-making in Britain. Comparative Politics, 25(3), 275-296.

Heredia, M., y Gené, M. (2009). Atributos y legitimidades del gabinete nacional: sociohistoria de los ministerios de Economía e Interior en la prensa (1930-2009). El Principe, 2, 109-135.

Iramain, L. (2012). Expansión del complejo económico estatal-privado y conformación de ámbitos privilegiados de acumulación durante la gestión liberal-corporativa. Los casos del sector vial y de la industria siderúrgica (Argentina, 1976-1981) (Tesis de doctorado inédita), Universidad de Buenos Aires, Facultad de Ciencias Sociales, Argentina.

Jajamovich, G., y Menazzi, L. (2012). Políticas urbanas en un contexto de dictadura militar. Algunos interrogantes a partir de la Ciudad de Buenos Aires (1976-1983). Revista Bitácora Urbano - Territorial, 20. 11-20.

Lucchini, A. (1980). Historia de la ingeniería argentina. Buenos Aires: Centro Argentino de Ingenieros.

Menazzi, L. (2013). Ciudad en dictadura. Procesos urbanos en la ciudad de Buenos Aires durante la última dictadura militar (1976-1983). Scripta Nova. Revista Electrónica de Geografía y Ciencias Sociales, XVII(429). S/ p. Recuperado de http://www.ub.edu/geocrit/sn/sn-429.htm

Menazzi, L. (2017). Entre las expectativas y la desmoralización: la Cámara Argentina de la Construcción ante la última dictadura militar. Revista H-Industria,11(20), 64-85. Recuperado de http://ojs.econ.uba.ar/ojs/index.php/Hind/article/view/985/1581

Menazzi, L. (2018). ¿Una comunidad profesional de la obra pública? Empresarios, ingenieros y funcionarios durante la última dictadura (1976-1981). Revista Perspectivas de Políticas Públicas, 8(159), en prensa. 
Müller, A., y Rapetti, M. (2001). Un quiebre olvidado: la política económica de Martínez de Hoz. Revista Ciclos, 21, 11-33.

Oszlak, O., y O’Donnell, G. (1981). Estado y Políticas Estatales en América Latina: hacia una estrategia de investigación. Documento CLACSO, 4, 1-44.

Palermo, S. (2006). Elite técnica y estado liberal: La creación de una administración moderna en los Ferrocarriles del Estado (1870-1910). Estudios Sociales. Revista Universitaria Semestral, XVI(30), 9-42.

Plotkin, M., y Zimmermann, E. (comp.) (2012). Los saberes del Estado. Volumen I. Buenos Aires: Edhasa.

Pucciarelli, A. (2004). Introducción. En A. Pucciarelli (coord.), Empresarios tecnócratas y militares (pp. 7-22). Buenos Aires: Siglo XXI.

Quiroga, H. (2005). El tiempo del Proceso. En J. Suriano (dir.), Nueva Historia Argentina, Tomo X, Dictadura y Democracia (1976 - 2001) (pp. 33-86). Buenos Aires: Sudamericana.

Regalsky, A., y Salerno, E. (2005). En los comienzos del Estado empresario: la inversión pública en ferrocarriles y obras sanitarias entre 1900 y 1928. Anuario del Centro de Estudios Históricos Prof. Carlos Segretti, 5, 247-272. Recuperado de http://www.cehsegreti.org.ar/archivos/FILE_00000305_1316802893.pdf

Rougier, M. (2015). El Complejo Militar-industrial, núcleo duro del Estado empresario y la industrialización en la Argentina. En A. Regalsky y M. Rougier [ed], Los derroteros del estado empresario en la Argentina (pp. 221-268). Caseros: Siglo XX - Eduntref.

Salerno, E. (2015). Los ingenieros, la tecnocracia de los Ferrocarriles del Estado. H-industri@, 9(16), 13-34. Recuperado de http://www.ojs.econ.uba.ar/ojs/index.php/H-ind/article/view/802/1439

Schvarzer, J. (1981). La expansión económica del estado subsidiario 1986 - 1981. Buenos Aires: CISEA.

Sidicaro, R. (1991). De la dictadura a la Democracia: Formatos de relación entre Estado y empresarios en la Argentina de la década del 80. Debate Laboral: Revista Americana e Italiana de Derecho del Trabajo, 8-9, 73-88.

Silvestri, G., y Gorelik, A. (2000). Ciudad y cultura urbana, 1976-1999: el fin de la expansión. En J. L. Romero, y L. A. Romero (dir.), Buenos Aires, historia de cuatro siglos, (pp. 461-499). Buenos Aires: Altamira.

Skocpol, T. (1985). El estado regresa al primer plano. Estrategias de análisis en la investigación actual. En B. Evans, D. Rueschemeyer, y T. Skocpol (comps.), Bringing the State Back in (pp. 3-43). Cambridge: Cambridge University Press.

Suriano, J. (2005). Introducción: Una Argentina diferente. En J. Suriano (dir), Nueva Historia Argentina, Tomo X, Dictadura y Democracia (1976 - 2001) (pp. 11-32). Buenos Aires: Sudamericana.

Suriano, J. (2012). El Departamento Nacional del Trabajo y la política laboral durante el primer gobierno de Yrigoyen. En M. Plotkin y E. Zimmermann (comps.), Los saberes del Estado (pp. 56-58). Buenos Aires: Edhasa.

Vezzetti, H. (2002). Pasado y presente. Guerra, dictadura y sociedad en la Argentina. Buenos Aires: Siglo XXI.

Weir, M. y Skocpol, T. (1993). Las estructuras del Estado: una respuesta 'keynesiana' a la Gran Depresión. Zona Abierta, 63/64, 71-122.

\section{Notas}

1 A lo largo del texto nos referiremos a la última dictadura militar indistintamente como Dictadura o Proceso.

2 En el área económica existen análisis que apuntan a identificar las líneas de continuidad y ruptura, discutiendo con perspectivas que ven sólo un corte abrupto a partir de 1976 (Castellani, 2009; Pucciarelli, 2004; Muller y Rappeti, 2001). Respecto a políticas urbanas, la articulación entre continuidades y rupturas es señalada por Silvestri y Gorelik (2000); Menazzi (2013), Menazzi (2012), y Dominguez Roca (2005).

3 Tal como señalan Schvarzer (1981) y otros autores, corresponde matizar el achicamiento del Estado en el período, en tanto los postulados liberales preconizados desde el área de Economía tuvieron dificultad para materializarse en el aparato estatal. El trabajo de Schvarzer demuestra que en vez de achicarse, o reducir su papel, diversas áreas del Estado expandieron su presencia en la economía.

4 Nos referiremos en singular al gobierno de Videla como un bloque que va de 1976 a 1981, si bien en realidad se trata de dos gestiones continuadas. 
5 Tal como desarrollaremos en el siguiente apartado, nos referimos al área de obra pública como un conjunto de agencias estatales ligadas al quehacer de la obra pública, independientemente de su escalafón y de su inserción en diversos ministerios. Esto se debe a que su jerarquía y subdivisión dentro del aparato estatal fue modificándose de modo incesante. En algunos momentos históricos hubieron varios ministerios vinculados a la obra pública mientras que en otros, como el que nos ocupa, se trató de un conjunto de secretarías, subsecretarías y entes desperdigados entre el Ministerio de Economía, el Ministerio de Bienestar Social, empresas estatales y entes autárquicos. Lo mismo acontece a nivel provincial, en que el área va variando de jerarquía de acuerdo a la provincia y al período, pudiendo ser un ministerio, una secretaría o una subsecretaría. Todo ello dificulta la delimitación del área y el seguimiento de los funcionarios a cargo. En este artículo indagaremos la trayectoria de veinte responsables del área tomando los cargos principales de la Secretaría de Estado de Transporte y Obras Públicas (secretario, subsecretarios, administrador de Dirección Nacional de Vialidad, Obras Sanitarias de la Nación y Ferrocarriles Argentinos), la Secretaría de Estado de Vivienda y Urbanismo (junto con la presidencia del Banco Hipotecario Nacional, cargo que va de la mano), la titularidad de algunas importantes empresas y entidades estatales como Agua y Energía Eléctrica, la Secretaría de Energía, Gas del Estado, Fabricaciones Militares, la Empresa Nacional de Telecomunicaciones y Servicios Eléctricos de Gran Buenos Aires, así como algunos titulares de la cartera de obras públicas a nivel provincial (Buenos Aires, Córdoba, Santa Fe, Mendoza, Entre Ríos y San Juan). Este conjunto de reparticiones manejaba una importantísima masa de recursos para realizar obras públicas, y tenían en muchos casos la potestad de regular las normas de la construcción en diversos rubros, realizar licitaciones o construir de de modo directo. En este sentido consideramos que estamos abarcando un universo muy relevante de actores en la obra pública del período. Los criterios para seleccionar a estos funcionarios fueron la relevancia de la repartición, la permanencia en sus puestos (hubo algunos cargos que sufrieron mucha rotación lo cual volvía muy difícil la caracterización de sus responsables) y la accesibilidad de la información.

6 En particular, haremos referencia a la CAC, una de las organizaciones empresarias más importantes del país en el período, que concentraba las demandas de los empresarios de la construcción. La AAC, una asociación integrada por reparticiones y funcionarios públicos así como empresas constructoras y ligadas a la vialidad que buscaba asesorar y participar en las políticas viales, y el CAI, organización profesional centenaria y tradicional, que agrupa a los ingenieros, profesionales íntimamente ligados (y que reivindican para sí como pertinencia profesional) a la obra pública.

7 Acerca de los derroteros del Estado argentino en tanto Estado empresario ver Regalsky y Salerno, (2005) y Bellini y Rougier (2008).

8 La construcción fue siempre una rama fundamental para la economía argentina. Históricamente conservó una participación de entre el $5 \%$ y el 7 \% del PBI, salvo contadas excepciones (CAC, 2006). El hecho de ser una industria mano de obra intensiva y con fuerte impacto en el resto de la economía la constituyó en uno de los mecanismos más utilizados de reactivación. La demanda estatal juega un rol central en esta industria, la cual llega, en algunos períodos, a una participación estatal del 50 \% (Schvarzer e Itscovitz, 1989) Los mercados de esta rama están sumamente segmentados en subsectores específicos, que difieren respecto a la tecnología necesaria, características de las obras y tipo de comitentes. Esto hace que los mecanismos de formación de precios y acumulación de capital también difieran. Se pueden consultar algunas caracterizaciones de esta industria en Vitelli $(1978,1976)$ Schvarzer e Itscovitz, (1989) y Serafinoff, (2011).

9 Esto queda en evidencia cuando se la compara con las credenciales y saberes valorados en otros ministerios. Así, como señala Gené, los saberes, credenciales, habilidades y trayectorias apreciados varían según el área estatal. Mientras que en algunas reparticiones "se reivindica un tipo de acción ideológicamente neutra y una legitimidad anclada en el conocimiento científico o el dominio de una técnica específica, [en otras se] movilizan saberes y legitimidades seculares como la militancia, la larga participación en uno o más partidos políticos, los lazos de confianza, la capacidad de decisión y el ejercicio de la autoridad” (Gené, 2011, p. 102).

10 Tal como señalan las autoras, "Ambos actores se han caracterizado por un discurso pretendidamente apolítico y que reclama para sí la capacidad de ubicarse por encima de los conflictos sociales” (Heredia y Gené, 2011, p. 4).

11 Tal como señala Lucchini (1981), los primeros ingenieros que actuaron en el Río de la Plata fueron militares. Las instituciones educativas del Ejército siguen dictando la carrera de Ingeniería y aún hoy existe el Arma de Ingenieros, cuya misión es apoyar al Ejército a partir de los saberes de la Ingeniería. A su vez, existe cierta afinidad electiva entre las preocupaciones de las fuerzas armadas y la ingeniería, por materializar el control y ocupación del territorio a través de las obras públicas.

12 Existía un acuerdo entre los actores empresarios, profesionales y estatales del sector de la obra pública en el período en valorar a la década del treinta como la etapa de oro para el sector. Esa década era el modelo por excelencia y la referencia ineludible a la hora de pensar cómo debían ser las reparticiones vinculadas a la obra pública. Así queda asentado en las declaraciones del presidente del CAI (Constantini, 1976), de la CAC (Polledo, 1976) y funcionarios públicos (Carmona, 1976).

13 Se trató de una demanda permanente de todas las instituciones vinculadas al sector y de los propios funcionarios a cargo de las reparticiones estatales ligadas a obra pública (ver, por ejemplo, Camba, 1980).

14 Tomamos esta conceptualización de Rougier (2015). 
15 Como todos los agrupamientos, se trata de una división analítica a los fines de este trabajo. Como criterio clasificador, se priorizaron los antecedentes profesionales. Algunos de los perfiles mencionados resultaban un poco más híbridos que los agrupamientos aquí realizados. A su vez, los grupos construidos serían diversos si se partiera de otros criterios clasificatorios. Canelo (2008), por ejemplo, analiza las internas militares. En este marco, uno de los grupos que caracteriza es el de los "duros", defensores de un modelo estatista y acérrimos defensores de las empresas de Estado. Allí agrupa algunos de los funcionarios civiles de carrera junto a funcionarios de origen militar. En nuestro caso, la agrupación difiere debido a que difieren los interrogantes teóricos.

16 Camba egresó de la Universidad de Buenos Aires en 1942, con el título de Ingeniero Civil. Fue profesor titular de la Universidad de Buenos Aires y La Plata, trabajó en Obras Sanitarias de la Nación, fue director de las obras de Ciudad Universitaria de Buenos Aires e integró el equipo de profesionales que elaboró el proyecto para la villa El Chocón de Hidronor S. A. Intervino en la redacción del Código de Edificación de la ciudad de Buenos Aires (encomendado por el CAI y la Sociedad Central de Arquitectos) y fue componente del grupo de trabajo que proyectó las obras del Complejo de Yaciretá - Apipé. Fue Subsecretario de Obras y Servicios Públicos ente 1969 y 1970 (Asociación Argentina de Carreteras, 1976a).

17 Batrosse egresó de la Universidad de Buenos Aires en 1938, con título de Ingeniero Civil. Desarrolló actividades varias en la Dirección de Obras Públicas de la Municipalidad de la Ciudad de Buenos Aires (entre 1933 y 1944), fue jefe del Departamento de Construcciones de Gendarmería Nacional (1938-1940), secretario general del Ministro de Obras Públicas de la Nación (1955-1957), subsecretario de Obras Públicas (1959-1960), director adjunto del grupo de planeamiento de los transportes, (organismo creado por acuerdo del gobierno argentino y el Banco Mundial) (1960-1963) y vocal del Directorio de Servicios Eléctricos del Gran Buenos Aires (SEGBA). Entre 1971 y 1972 desempeñó el cargo de Asesor de la Comisión Técnica Mixta de Salto Grande. Intervino en la confección de diversos proyectos tales como: nueva Central Hidroeléctrica en la presa Cabra Corral, línea de alta tensión de interconexión de los sistemas eléctricos de Tucumán, central eléctrica del Dique Ullum y revisión del proyecto de Salto Grande. Presidió, además, la comisión que tuvo a su cargo las negociaciones del contrato para la ejecución de las obras del complejo Zárate Brazo Largo, y se desempeñó como docente en numerosas universidades (Asociación Argentina de Carreteras, 1976b).

18 Ogueta egresó de la Universidad de Buenos Aires en 1963, con título de Ingeniero Civil. Realizó estudios de especialización en planeamiento del transporte urbano en organismos del exterior. En 1970 fue director nacional de Programación y Control del Ministerio de Obras y Servicios Públicos, tuvo a su cargo la dirección del Estudio del Transporte de la Región Metropolitana de Buenos Aires, y se desempeñó como gerente de Transportes y Comunicaciones de la Corporación de Empresas, cargo que retuvo al asumir la Subsecretaría de Transporte en 1976. En paralelo, se desempeñó como docente universitario. Publicó trabajos sobre la ejecución y diseño de obras por el sistema de peajes, planeamiento del transporte, diseño de carreteras por computadoras y economía del transporte. Al asumir dirigía la revista Carreteras, de la AAC (Asociación Argentina de Carreteras, 1976b).

19 Ballester era Ingeniero Civil egresado de la Universidad de Buenos Aires. Fue miembro de la Dirección de las obras hidroeléctricas del Complejo el Chocón Cerros Colorados entre 1969 y 1976 y director suplente de Hidroeléctrica Norpatagónica S. A. (entre 1967 y 1969) (Ballester, 2018).

$20 \mathrm{El}$ administrador general del período fue el Ing. Pedro Viciens, ingeniero civil, recibido en la UBA en 1942. Viciens era una eminencia en el universo de la Ingeniería. Era profesor titular en la UBA y había cursado estudios en el MIT de Massachusetts. Se había desempeñado como director técnico de la Compañía Ítalo Argentina de Electricidad (Reggini, 2018, Fundación Konex, 2018).

21 El secretario de Energía entre 1977 y 1981 fue el ingeniero civil Daniel Alberto Brunella, quien previamente se había desempeñado como administrador general de YPF en 1967 (Philip, 1982). Castellani señala su inserción empresarial en Renault y Ericsson (Castellani, 2009).

22 Gas del Estado quedó a cargo del ingeniero civil Gabriel Meoli, quien había sido rector de la UTN entre 1955 y 1959 , autoridad de la Academia Nacional de Ingeniería y vicepresidente de SEGBA (Academia Nacional de Ingeniería, 2005; Universidad Tecnológica Nacional, 2018). En este caso también, Castellani señala su inserción empresarial en la firma Astra (Castellani, 2009).

23 El secretario de Estado de Vivienda y Urbanismo y presidente del Banco Hipotecario Nacional (cargos que se asumían de modo conjunto) fue el Ing. Carlos Alberto Canedo, pero a partir de 1978. Ingeniero civil, recibido en la Universidad de La Plata, con posgrado en Ingeniería Sanitaria de la Universidad de Buenos Aires y cargo docente en la primera. Su caso resulta un tanto más híbrido, en tanto al momento de asumir tenía una extensa trayectoria en cargos públicos y en empresas privadas en diversos rubros como construcciones aeronáuticas, agrimensura, ingeniería sanitaria y obras públicas $(C A I, 1979)$. Previo a él, se desempeñó en ese cargo el Arq. Máximo Vázquez Llona, quien poseía experiencia en cargos públicos, como el de Secretario de Obras Públicas y Urbanismo de la Municipalidad de la Ciudad de Buenos Aires durante la dictadura de Onganía. 
24 El ingeniero Roberto Agüero Olmos se hizo cargo de la Dirección de Vialidad de la Provincia de Buenos Aires a partir de 1977. Había sido administrador de la Dirección Nacional de Vialidad entre 1969 y 1973, y a partir de 1976 se convirtió en asesor de la Dirección Nacional de Vialidad (Asociación Argentina de Carreteras, 1976c).

25 El Ing. Coria Jofré (Ing. civil e hidráulico) asumió la Secretaría de Estado de Obra Pública en San Juan habiendo desarrollado previamente una extensa carrera en la burocracia estatal. A partir de 1961 se incorporó como ingeniero proyectista en la Dirección General de Obras Públicas de su provincia. Pasó a ser luego jefe de Departamento de Planeamiento y posteriormente jefe de Hidrología. Además, tenía estudios de posgrado, experiencia docente y en investigación (CAC, 1977a, Coria Jofré, 2018).

26 El Ingeniero Carmona (Ing. civil, de vías de comunicación y agrimensor) se desempeñó en la Dirección Provincial de Vialidad de San Juan y en la Dirección General de Obras Públicas entre 1957 y 1958. Entre 1964 y 1976 desarrolló su carrera en VIALCO, una de las más importantes empresas del submercado vial del período (Iramain, 2012 analiza con más detalle la trayectoria profesional de Carmona).

27 Lanusse (ingeniero civil recibido en la UBA en 1935) se desempeñó como director de obra de numerosos edificios y obras de ingeniería y dirigió varias empresas vinculadas al sector de la construcción. En la función pública se desempeñó como presidente de la empresa Ferrocarriles del Estado en 1962, secretario de Transporte de la Nación entre 1966 y 1967 , ministro de Defensa entre 1967 y 1968. Asimismo, tuvo intensas participaciones en diversas agrupaciones empresarias y se desempeñó como docente. Como se observa, se trata de una trayectoria híbrida, en que se intercalan actividades públicas y privadas $(C A C, 1981 b)$.

28 Gorostiaga, hijo de un prominente empresario del mismo nombre heredó la Empresa Argentina de Cemento Armado junto a su hermano. Dirigió la construcción de obras como las plantas de Celulosa Argentina, Astilleros Costaguta, Ford Argentina, La Bernalesa, Cine Metro, Banco de Avellaneda, Puente Pueyrredon, y Puente Paysandú-Colón, Central Termoeléctrica Costanera, Túnel de Av. del Libertador, elevadores de granos de Rosario entre otras. La Empresa Argentina de Cemento Armado (EACA) era una de las más importantes del período. Fundada en 1922, había realizado infinidad de obras como las mencionadas con anterioridad y viviendas, oficinas, estadios, plantas fabriles, etc. Durante el período se le otorgaron importantes obras, como las Autopistas Urbanas de la ciudad de Buenos Aires (CAC, 1980).

29 El caso de Carmona constituye una excepción, puesto que acompañó los dos mandatos de Videla, al igual que sus superiores en la Subsecretaría de Transporte y Obras Públicas. Muchos de los funcionarios de origen empresario querían prestar apoyo al "Proceso" asumiendo cargos, pero terminaban volviendo a su práctica privada luego de un breve período. En el caso de los ministros y/o secretarios de provincias, su alta rotación pudo deberse a las dinámicas propias de los gobiernos provinciales durante el Proceso, en que también hubo mucho recambio de gobernadores (sobre sus perfiles, ver Canelo, 2013).

30 Urricarriet era un Ingeniero Militar con vastísima trayectoria en cargos públicos. Cumplió funciones en el Estado Mayor General del Ejército, en la Inspección General de Instrucción, en la Dirección General de Ingenieros, en el Batallón de Ingenieros de Construcciones con asiento en Presidencia de la Nación. Fue administrador del Ferrocarril Sarmiento, secretario general de la Dirección General de Fabricaciones Militares, comandante de ingenieros del Comando en Jefe del Ejército. Ya en 1975 se desempeñó como presidente del directorio y director general de Fabricaciones Militares hasta 1979. En 1976 también pasó a desempeñarse como presidente del directorio de Petroquímica Bahía Blanca S. A. Desde fines de 1980 ocupó la presidencia del directorio de ATANOR y de la Academia de Ingeniería de la Provincia de Buenos Aires $(C A C, 1981 \mathrm{a})$.

31 Previamente, había dirigido el Arsenal Naval de Buenos Aires y había sido presidente de Tandanor.

32 Corrado (Ingeniero militar) se había desempeñado desde 1975 como director de la Escuela de Comunicaciones y a partir de 1979 como secretario de Comunicaciones (Canelo, 2008).

33 En el caso de Mendoza, se nombró al coronel Carlos Benito Pajariño y, en el caso de Entre Ríos, al capitán Rodolfo Carponi (Revista de la Cámara Argentina de la Construcción, 1977 b y $1977 \mathrm{c}$ ).

$34 \mathrm{El}$ argumento de Ballent (2012), sin embargo, es más complejo, en tanto ella da cuenta de cómo la trayectoria estadocéntrica era la representación más prestigiosa, de modo que los pasajes por el universo privado eran minimizados en el relato de las trayectorias en diversos órganos de prensa. Se volverá sobre esta cuestión más adelante.

35 La coincidencia ideológica de muchas agrupaciones patronales con los postulados del régimen, el acceso a algunos puestos de decisión por parte de empresarios de diversas ramas y la cruzada contra la subversión y la "restauración del orden" supusieron un fuerte apoyo inicial de las asociaciones empresarias más importantes a la dictadura (Birle, 1997). Sin embargo, algunos autores señalan también cierta impermeabilidad y desconfianza frente a los empresarios por parte de sectores del gobierno militar, la influencia limitada que éstos pudieron ejercer en las decisiones gubernamentales, y los efectos muy heterogéneos de la política económica sobre la industria, que dependían del sector y tamaño de la empresa (Sidicaro, 1991; Beltrán, 2007; Acuña, 1988).

36 En trabajos previos (Menazzi, 2018) se analizan los posicionamientos de la CAC respecto al Proceso de Reorganización Nacional y su apoyo a posturas liberales y antiestatistas que en ocasiones colisionaban con sus propios intereses sectoriales. 
37 La Revista CAI Informa, órgano del CAI, sacaba periódicamente duras editoriales y notas críticas acerca de la política económica llevada adelante en el período, defendiendo posturas industrialistas y antiaperturistas.

38 Esta autorrepresentación no impedía que las organizaciones profesionales de los ingenieros intervinieran en disputas políticas, pero, desde su propia perspectiva, esto se hacía desde un lugar neutral. Por ejemplo, cuando realizaban críticas a la dictadura afirmaban que lo hacían "ni en contra ni a favor de ningún Proceso, sólo por el interés nacional” (Constantini, 1980, p. 11). Por su parte, los integrantes de la dictadura, también consideraban que los ingenieros tenían un rol técnico que cumplir, y que eran interlocutores válidos para el régimen. Así, se convocó al CAI al Diálogo Político iniciado en 1980. La representación de los ingenieros como portadores de racionalidad técnica versus partidismos, así como su rol como merecedores "naturales" de ciertos cargos se reitera en diversos períodos y escenarios, tal como emerge de Ballent (2008).

39 Un ejemplo de estos desacuerdos queda en evidencia hacia el final de la segunda gestión de Videla, a comienzos de 1981. Constantini, presidente del CAI, realizó duras afirmaciones en una conferencia de prensa: "si se destruye el aparato productivo a través de la política económica implantada hace cinco años se destruyen nuestras estructuras financieras y se destruye el campo, organismo vital para poder mantener nuestras relaciones de intercambio internacional (...) hemos destruido totalmente nuestro país" (Constantini, 1981, p. 7). A partir de estas afirmaciones, un grupo de socios solicitó al presidente del CAI se abstenga hacer declaraciones políticas. Entre los firmantes, estaba Marghetti, quien fuera presidente de la CAC entre 1976 y 1980. A esta nota respondió la comisión directiva y otra nota firmada por numerosos socios en apoyo a Constantini. Entre los firmantes de la segunda nota está el Ing. Alesso, presidente de la AAC y vicepresidente de la CAC. Es decir, como se advierte, este conflicto atravesó a las distintas entidades vinculadas al quehacer de la construcción, a partir de un desacuerdo de larga data.

40 Desde la perspectiva de los empresarios, los fondos genuinos eran aquellos que provenían de impuestos específicos que se derivaban automáticamente al sector, como por ejemplo, el impuesto a los combustibles que debía derivarse a Vialidad. La queja era contra la distorsión de estos impuestos, en tanto eran desviados y utilizados para otras cosas y se suplía la carencia de fondos con aportes del Tesoro, es decir, con mecanismos sujetos a la discrecionalidad política desde la perspectiva de los empresarios.

41 Este viraje en la era Viola resulta sumamente interesante, en tanto autores como Sidicaro (1991) afirman que "El formato Viola presentó como característica la corporativización empresaria del Estado. Este proyecto se operacionalizó desarticulando el Ministerio de Economía, que en los cuatro años anteriores había sido una de las piezas clave del intento de cambio social autoritario. En su lugar se crearon un conjunto de ministerios (agricultura, industria y comercio), y al frente de cada uno de ellos se puso a representantes de los distintos sectores empresarios que durante el gobierno de Videla habían criticado la política seguida por Martínez de Hoz" (Sidicaro, 1991, p. 77). Resulta interesante que, en el caso de obra pública, operó una lógica distinta, en tanto las reparticiones parecen, en su mayoría, haber quedado en manos de funcionarios más cercanos al intervencionismo estatal y las empresas de Estado. Es decir, se amplió la participación de militares en detrimento de funcionarios de carrera y empresarios.

42 Para un análisis de los perfiles del gabinete de ministros durante el Proceso, ver Canelo (2016). 